Jurnal Media Agribisnis Vol. 3 No. 2 Tahun 2018 Hal. 90 - 97

Media Komunikasi Hasil Penelitian Bidang Ilmu Agribisnis ISSN print 2548-7027

ISSN online 2541-6898

\title{
DAMPAK PROGRAM GERAKAN TURUN KE SAWAH (GERUNWAH) \\ TERHADAP PENINGKATAN PRODUKSI DAN KESEJAHTERAAN PETANI DI KELURAHAN DUSUN BARU KECAMATAN TABIR KABUPATEN MERANGIN
}

\author{
Mulyani $^{1),}$ Wiwin Alawiyah ${ }^{2)}$ \\ Program Studi Agribisnis, Fakultas Pertanian Universitas Batanghari \\ Jl. Slamet Riyadi-Broni, Jambi. 36122. Tel. +6274160103 \\ ${ }^{1)}$ email korespondensi: $\underline{m}$ yaniez@yahoo.co.id
}

\begin{abstract}
This research was conducted on February to May 2018 in "Dususn Baru” Village "Tabir" District, "Merangin" Regency and focused on Wetland paddy farmers as the participant of the government program called "Gerakan Turun Ke Sawah" (GERUNWAH). This research was concerned on the impact of its programs toward to the rice production level and the farmers welfare. Descriptive analysis and mean difference test (mean test) were used in this research as the analisis method. This research was conducted by survey method which completed by primary and secondary data type e.g. the data before and after the program implementation. Samples were determined by simple random sampling method. The result showed that the GERUNWAH program gave a significant effect on the paddy production increasing in "Dusu Baru" Village "Tabir" District "Merangin" Regency

Keywords: GERUNWAH, rice production, farmer welfare
\end{abstract}

\begin{abstract}
Abstrak
Penelitian ini dilakukan di Kelurahan Dusu Baru, Kecamatan Tabir, Kabupaten Merangin dan difokuskan pada petani padi sawah sebagai partisipan dalam kegiatan program pemerintah bernama "Gerakan Turun Ke Sawah" (GERUNWAH). Ruang lingkup penelitian ini difokuskan pada dampak program tersebut terhadap tingkat produksi dan kesejahteraan petani. Metode analisis yang digunakan adalah analisis deskriptif, dan Uji perbedaan rata-rata (uji mean). Penelitian dilakukan dengan metode survey yang dilengkapi dengan jenis data primer dan sekunder yaitu berupa data sebelum dan sesudah pelaksanaan program. Sampel ditarik secara simple random sampling. Hasil penelitian menunjukkan Program GERUNWAH berpengaruh signifikan terhadap peningkatan produksi padi di Kelurahan Dusu Baru, Kecamatan Tabir Kabupaten Merangin.
\end{abstract}

Kata kunci: GERUNWAH, produksi padi, kesejahteraan petani

\section{PENDAHULUAN}

Padi merupakan tanaman pangan politis dan strategis yang dibutuhkan oleh masyarakat di Indonesia sebagai bahan makanan pokok utama sumber karbohidrat. Akan tetapi pemerintah masih dihadapkan pada ketergantungan terhadap impor dari negara lain. Usaha tani padi menyediakan lapangan pekerjaan dan sebagai sumber pendapatan bagi sekitar 21 juta rumah tangga pertanian.

Diterbitkan Oleh Program Studi Agribisnis Fakultas Pertanian Universitas Batanghari Jambi

Halaman 90 
Jurnal Media Agribisnis Vol. 3 No. 2 Tahun 2018 Hal. 90 - 97

Media Komunikasi Hasil Penelitian Bidang Ilmu Agribisnis

ISSN print 2548-7027

ISSN online 2541-6898

Hingga saat ini lahan sawah tetap menjadi tulang punggung pengadaan produksi padi nasional. Hal ini terkait dengan tingkat kesuburan lahan, ketersediaan air, dan infrastruktur yang lebih baik serta pengelolaan lahan dan tanaman yang relatif lebih mudah di lahan sawah dibandingkan dengan agroekosistem lainnya. Oleh karena itu, program peningkatan produksi padi lebih diarahkan ke lahan sawah. Namun, saat ini sebagian lahan sawah mengalami penurunan produktivitas, sebagaimana tercermin dari pelandaian laju produksi padi (L Sanny,2010).

Ketahanan pangan merupakan masalah nasional yang perlu segera dicarikan solusinya. Berbagai kebijakan sudah dilakukan pemerintah dalam rangka bentuk usaha untuk meningkatkan produksi tanaman pangan termasuk padi. Salah satu dari program tersebut adalah program gerakan turun ke sawah berupa pencetakan sawah baru ataupun lama dengan cara memberikan bantuan benih, pupuk, dan obat-obatan serta peralatan yang mendukung produksi padi. Oleh karena itu perlu dilakukan penelitian yang mendalam untuk menilai apakah bentuk program tersebut berdampak atau tidak terhadap petani. Baik dari aspek produksi maupun aspek kesejahteraan petani padi.

Luas lahan sawah di Provinsi Jambi pada tahun 2016 seluas 133.868 hektar (BPS,2017). Dari 11 kabupaten/kota yang ada di Provinsi Jambi Merangin menempati posisi kedua dengan luas lahan sawah irigasi $7.388 \mathrm{Ha}$ dan Non Irigasi seluas 4.923 Ha. Pada tahun 2017 ini, Kabupaten Merangin kembali mendapatkan bantuan cetak sawah baru seluas 500 hektar dari Pusat(metrojambi.com). Bantuan cetak sawah baru itu, lengkap dengan bantuan pembangunan irigasi dan pengairan sawah. Pada tahun 2016, Kabupaten Merangin berada diperingkat 28 nasional dari sebanyak 530 kabupaten di Indonesia (Bupati Merangin, 2017).

Tabel 1. Luas Lahan Sawah Menurut Kabupaten/Kota dan Jenis Pengairan di Provinsi Jambi (hektar), 2016.

\begin{tabular}{llccc}
\hline No & \multicolumn{1}{c}{$\begin{array}{c}\text { Kabupaten/Kota } \\
(\mathbf{1})\end{array}$} & $\begin{array}{c}\text { Irigasi } \\
(\mathbf{2})\end{array}$ & $\begin{array}{c}\text { Non Irigasi } \\
\mathbf{( 3 )}\end{array}$ & $\begin{array}{c}\text { Jumlah Total } \\
\mathbf{( 4 )}\end{array}$ \\
\hline \multicolumn{1}{c}{ Kabupaten/Kota } & & & \\
1. & Kerinci & 15.205 & 3.710 & 18.915 \\
2. & Merangin & 7.388 & 4.923 & 12.311 \\
3. & Sarolangun & 1.909 & 4.806 & 6.715 \\
4. & Batang Hari & 352 & 17.002 & 17.354 \\
5. & Muaro Jambi & 840 & 22.354 & 23.194 \\
6. & Tanjab Timur & 0 & 22.637 & 22.637 \\
7. & Tanjab Barat & 1.021 & 9.298 & 10.319 \\
8. & Tebo & 1.230 & 9.155 & 10.385 \\
9. & Bungo & 6.604 & 566 & 7.170 \\
10. & Kota Jambi & 0 & 1.349 & 1.349 \\
11. & Kota Sungai Penuh & 1.671 & 1.848 & 3.519 \\
& Jambi & 36.220 & 97.648 & 133.868 \\
\hline
\end{tabular}

Sumber: website Kabupaten Merangin, 2018 
Jurnal Media Agribisnis Vol. 3 No. 2 Tahun 2018 Hal. 90 - 97

Media Komunikasi Hasil Penelitian Bidang Ilmu Agribisnis

ISSN print 2548-7027

ISSN online 2541-6898

Gerakan turun ke sawah yang diterapkan oleh Bupati Merangin bertujuan untuk mencapai surplus beras di kabupaten merangin, dengan kondisi harga karet dan sawit yang belum stabil Banyak masyarakat memilih turun ke sawah karena panen padi satu hektarnya lebih menguntungkan dari satu hekar sawit atau pun karet (Bupati Merangin). Oleh karena itu, penelitian ini hendak melakukan analisis mengenai dampak kebijakan tersebut terhadap tingkat produksi dan kesejahteraan petani di kabupaten Merangin.

\section{METODOLOGI PENELITIAN}

Penelitian ini adalah mengkaji dampak pelaksanaan program gerakan turun ke sawah terhadap produksi petani padi sawah di Dusun Baru Kecamatan Tabir Kabupaten Merangin dan terhadap kesejahteraan petani di wilayah tersebut.

Penelitian ini dilakukan di Dusun Baru Kecamatan Tabir Kabupaten Merangin difokuskan pada Petani padi sawah yang mengikuti kegiatan gerakan turun ke sawah yang dicanangkan pemerintah daerah. Ruang lingkup penelitian ini difokuskan pada kegiatan menganalisis dampak program kebijakan pemerintah daerah berupa gerakan turun ke sawah untuk melihat apakah terdapat pengaruh terhadap ringkat produksi petani padi sawah dan kesejahteraan petani padi sawah di wilayah tersebut.

Penelitian ini dilaksanakan pada bulan Februari sampai Juni 2018. Adapun data yang dikumpulkan pada penelitian ini adalah:

1. Pendapatan $(\mathrm{Rp})$

2. Produksi padi $(\mathrm{Kg})$

3. Produktivitas ( \%)

4. Luas Lahan (Ha)

5. Jumlah tenaga kerja (orang)

6. Pupuk (Rp)

7. Obat-obatan $(\mathrm{Rp})$

8. Teknologi (Ada/tidak menggunakan alat yang modern)

Metode penelitian yang digunakan adalah metode penelitian analisis deskriptif, dengan uji Wilcoxon. Data yang digunakan adalah berupa data primer dan data sekunder yaitu data sebelum dan sesudah pelaksanaan program gerakan turun ke sawah. Penelitian dilakukan melalui metode survey ke tempat pelaksanaan kegiatan tersebut.

Metode yang digunakan untuk penarikan sampel pada penelitian ini adalah simple random sampling. Dalam penelitian ini populasi adalah petani yang mengikuti gerakan turun ke sawah di Kabupaten Merangin. Penentuan lokasi penelitian secara purposive, yaitu wilayah Rantau Panjang Kabupaten Merangin.

Data yang sudah dikumpulkan dianalisis menggunakan system tabulasi dan diuji dengan uji wilxocon Rank Test untuk melihat apakah terdapat perbedaan tingkat produksi petani sesudah mengikuti gerunwah dengan sebelum mengikuti gerunwah. 
Jurnal Media Agribisnis Vol. 3 No. 2 Tahun 2018 Hal. 90 - 97

Media Komunikasi Hasil Penelitian Bidang Ilmu Agribisnis

ISSN print 2548-7027

ISSN online 2541-6898

Hipotesis:

$H_{0}: \mathrm{P}\left(X_{i}\right) \geq \mathrm{P}\left(Y_{i}\right)$ maka Program Gerunwah tidak dapat meningkatkan produksi petani

$H_{1}: \mathrm{P}\left(X_{i}\right)<\mathrm{P}\left(Y_{i}\right)$ maka Program Gerunwah dapat meningkatkan produksi petani

Kriteria:

$\mathrm{T}+/ \mathrm{T}-$ terkecil $\geq \mathrm{T}$ tabel $(\mathrm{W} \alpha)$ maka $H_{0}$ tidak dapat ditolak

$\mathrm{T}+/ \mathrm{T}$ - terkecil $<\mathrm{T}$ tabel $(\mathrm{W} \alpha)$ maka $H_{0}$ ditolak

Sedangkan untuk melihat dampak program gerunwah terhadap kesejahteraan petani dilakukan uji Sign Test.

Hipotesis:

$H_{0}: \mathrm{P}(+)=\mathrm{P}(-) \quad$ maka tidak ada perubahan kesejahteraan petani setelah mengikuti gerunwah

$H_{1}: \mathrm{P}(+) \neq \mathrm{P}(-) \quad$ maka ada perubahan kesejahteraan petani setelah mengikuti gerunwah

Kriteria:

$\mathrm{t}<\mathrm{T}<\mathrm{n}-\mathrm{t}$

$\mathrm{T} \leq \mathrm{t}$ atau $\mathrm{T} \geq \mathrm{n}-\mathrm{t}$

maka $H_{0}$ tidak dapat ditolak

maka $H_{0}$ ditolak

Konsep Pengukuran dalam penelitian ini adalah sebagai berikut:

1. Jumlah Produksi atau output yang dimaksud adalah jumlah total produksi padi sawah yang dihasilkan pada satu kali masa panen satuan kilogram $(\mathrm{kg})$

2. Luas lahan adalah luas areal tanam padi sawah yang dimiliki/disewa oleh setiap petani untuk budidaya padi sawah dalam satuan meter persegi $\left(\mathrm{m}^{2}\right)$

3. Tenaga kerja adalah jumlah jam tenaga kerja yang digunakan pada usaha budidaya padi sawah dalam satu kali masa tanam (jam kerja)

4. Biaya produksi adalah seluruh biaya yang dikeluarkan oleh petani yang merupakan biaya tetap dan variabel dalam satu musim tanam (Rp)

5. Harga jual adalah besarnya nilai penjualan padi yang diterima oleh petani.(Rp).

6. Pendapatan petani adalah penerimaan yang diperoleh dari usaha budidaya padi sawah dikurangi seluruh biaya yang dikeluarkan usaha budidaya padi sawah (Rp).

\section{HASIL DAN PEMBAHASAN}

Sebagian besar wilayah di Kelurahan Dusun Baru Kecamatan Tabir digunakan untuk sektor pertanian, perikanan dan kehutanan/perusahaan tertentu pertambangan atau usaha lainnya). Keadaan sumberdaya alam Kelurahan Dusus Baru Kecamatan Tabir berada pada ketinggian 80-125 m dpl, dengan kondisi tanah datar $80 \%$, gelombang $20 \%$ dan berbukit $0 \%$. Pembagian lahan menurut luas potensi pertanian dapat dilihat pada tabel 2 . 
Jurnal Media Agribisnis Vol. 3 No. 2 Tahun 2018 Hal. 90 - 97

Media Komunikasi Hasil Penelitian Bidang Ilmu Agribisnis

ISSN print 2548-7027

ISSN online 2541-6898

Tabel 2. Data Luas Potensi Lahan Pertanian Kelurahan Dusun Baru Kecamatan Tabir berdasarkan Jenis Lahan Tahun 2017

\begin{tabular}{clcc}
\hline No & \multicolumn{1}{c}{ Jenis Lahan } & Luas (ha) & Persentase \\
\hline 1 & Lahan Basah & 1.727 & 18,20 \\
2 & Lahan Kering & 7.773 & 81,80 \\
& Jumlah & 9.500 & 100 \\
\hline
\end{tabular}

Sumber : Dinas Tanaman Pangan dan Hortikultura Kabupaten Merangin, 2017

Petani padi di Dusun Baru sebanyak 2,7 \% menggunakan irigasi desa yakni seluas 252 Ha sebagaimana dirinci dalam tabel dibawah ini:

Tabel 3. Data Luas Lahan di Kelurahan Dusun Baru berdasarkan penggunaannya tahun 2017

\begin{tabular}{llcc}
\hline No $\quad$ Jenis Penggunaan Tanah & Luas (Ha) & $\begin{array}{c}\text { Prosentaase } \\
(\%)\end{array}$ \\
\hline
\end{tabular}

1 Lahan Basah

a. Sawah

- Irigasi Teknis

- Irigasi Setengah Teknis

- Irigasi Sederhana

- Irigasi Desa

b. Tadah Hujan

252

2,7

c. Lebak/Rawa

450

4,7

d. Polder (DAS)

300

3,7

e. Kolam

175

1,7

f. Perairan Umum

5

0,5

545

5,8

\section{Lahan Kering}

- Pekarangan

240

2,5

- Tegalan

654

6,8

- Ladang/Huma

1407,5

14,5

- Perkebunan

1381,5

14,1

- Padang Pengembalaan

3507

37

- Hutan Rakyat

62

0,6

- Hutan Negara

$-$

- Lahan Tidur

521

- Lain-lain

9.500

5,4

Jumlah

9.500

100

Sumber : Dinas Tanaman Pangan dan Hortikultura Kabupaten Merangin, 2017

a. Produksi Petani Padi Sawah

Berdasarkan data yang sudah diolah dengan software SPSS menggunakan uji Wilcoxon Signed Test untuk melihat apakah ada perbedaan tingkat produksi di kelurahan Dusun Baru kecamatan Tabir Kabupaten Merangin, didapatlah hasil output dibawah ini: 
Jurnal Media Agribisnis Vol. 3 No. 2 Tahun 2018 Hal. 90 - 97

Media Komunikasi Hasil Penelitian Bidang Ilmu Agribisnis

ISSN print 2548-7027

ISSN online 2541-6898

Tabel 2. Hasil Uji Statistik Wilcoxon Signed Ranks Test

\begin{tabular}{|ll|r|r|r|}
\hline \multicolumn{1}{|c|}{ Ranks } \\
\hline SESUDAH - & Negative & $6^{\mathrm{a}}$ & \multicolumn{1}{c|}{$\begin{array}{c}\text { Mean } \\
\text { Rank }\end{array}$} & $\begin{array}{c}\text { Sum of } \\
\text { Ranks }\end{array}$ \\
SEBELUM & Ranks & & & 24.08 \\
& Positive Ranks & $44^{\mathrm{b}}$ & 28.42 & 1250.50 \\
& Ties & $2^{\mathrm{c}}$ & & \\
& Total & 52 & & \\
\hline
\end{tabular}

a. SESUDAH $<$ SEBELUM

b. SESUDAH > SEBELUM

c. SESUDAH $=$ SEBELUM

\begin{tabular}{|l|r|}
\hline \multicolumn{1}{c|}{ Test Statistics ${ }^{\mathrm{b}}$} \\
\hline & $\begin{array}{r}\text { SESUDAH - } \\
\text { SEBELUM }\end{array}$ \\
\hline $\begin{array}{l}\text { Z } \\
\text { Asymp. Sig. (2- } \\
\text { tailed) }\end{array}$ & $-5.927^{\mathrm{a}}$ \\
\hline
\end{tabular}

a. Based on negative ranks.

b. Wilcoxon Signed Ranks Test

Berdasarkan hasil analisis Uji wilcoxon diketahui bahwa terdapat perbedaan nyata (selang kepercayaan $95 \%$ ) adanya perbedaan tingkat produksi sebelum dan sesudah adanya gerakan turun ke sawah di Dusun Baru kec. Tabir Kabupaten Merangin. Hal ini dikarenakan terlihat bahwa nilai Asymp.Sig. (2tailed) lebih kecil dari 0,05 maka Ha diterima.

Berdasarkan hasil penelitian diketahui bahwa terdapat peningkatan hasil produksi petani padi setelah adanya gerakan turun ke sawah (GERUNWAH) dilokasi penelitian. Hal ini sejalan dengan hasil penelitian sebelumnya, dimana tingkat produktivitas rata-rata sebelum adanya gerakan turun ke sawah di kabupaten Sarolangun lebih rendah jika dibandingkan dengan sesudah adanya gerakan turun kesawah (Salfitri,2010). Kebijakan pemerintah daerah melalui program-program yang diberikan untuk petani memang merupakan salah satu kekuatan dalam analisis SWOT. Dimana perlu adanya penyuluhan bagi petani sehingga mempunyai ruang gerak dan inovasi yang memadai dalam mengakses informasi, produksi dan pemasaran menuju pertanian yang berbasis agribisnis dan berdaya saing tinggi (Mantiri, 2016).

Petani dalam kegiatan produksinya tidak semuanya menggunakan tenaga kerja berbayar. Beberapa kegiatan dilakukan sendiri, misalnya kegiatan membersihkan lahan, membuat pematang sawah, memupuk, dan menyemprot. Selain itu, salah satu kearifan lokal yang masih dijaga oleh petani di Dusun Baru adalah gotong royong. Beberapa kegiatan dalam proses produksi dilakukan secara bergotong royong diantaranya adalah pada saat memanen padi, membuat parit, 
Jurnal Media Agribisnis Vol. 3 No. 2 Tahun 2018 Hal. 90 - 97

Media Komunikasi Hasil Penelitian Bidang Ilmu Agribisnis

ISSN print 2548-7027

ISSN online 2541-6898

menanam padi, dan mengumpulkan malai. Sehingga tidak ada biaya berupa upah tenaga kerja yang harus dikeluarkan petani pada saat melakukan hal - hal tadi. Dengan adanya program Gerakan Turun ke sawah (GERUNWAH) ini biaya perawatan dan pengairan dibantu oleh pemerintah, begitu juga benih semuanya disediakan oleh pemerintah. Hal ini tentunya sangat membantu petani dari aspek pembiayaan dalam kegiatan usaha tani padi. Pemerintah kabupaten Merangin juga membantu perluasan lahan usahatani padi sehingga dengan ini pemerintah berupaya melakukan ekstensifikasi guna meningkatkan produksi padi ini. Perkembangan luas panen berpotensi untuk mempengaruhi besarnya produksi beras (Edison, 2012).

\section{b. Kesejahteraan Petani}

Kesejahteraan petani yang telah direncanakan diteliti pada penelitian ini adalah yang direpresentasikan melalui tingkat pendapatan petani yang mengikuti program gerakan turun ke sawah (Gerunwah) di Dusun Baru Kecamatan Tabir Kabupaten Merangin yang salah satu komponennya adalah penerimaan dari hasil penjualan padi yang telah dipanen oleh petani padi. Akan tetapi, setelah dilakukan penelitian ternyata petani di wilayah penelitian tidak menjual hasil panennya melainkan dikonsumsi sendiri. Hal ini dilakukan petani karena tingginya harga beras ditingkat konsumen. Sehingga petani diwilayah penelitian merasa rugi jika harus menjual hasil panennya dan membeli kembali beras ke pedagang untuk dikonsumsi. Sedangkan jika dibandingkan dengan dampak Gerakan Turun ke Sawah di Kabupaten Sarolangun terdapat perbedaan pendapatan rata- rata tingkat pendapatan petani sawah antara sebelum dan sesudah adanya program ini. Dimana, rerata pendapatan petani sebelum program lebih rendah (Rp 3.738.386), dari pada setelah program (sebesar Rp 7.379.924) (Salfitri,2010).

\section{KESIMPULAN}

Kesimpulan yang didapat dari hasil penelitian ini adalah bahwa terdapat perbedaan nyata pada tingkat produksi petani padi yang mengikuti program Gerakan Turun ke Sawah (GERUNWAH) di Dusun Baru, Merangin. Dimana, terjadi peningkatan produksi setelah mengikuti program tersebut.

\section{DAFTAR PUSTAKA}

Abd. Rahim dan Diah Retno Dwi Hastuti 2007, EkonomikaPertanian,Pengantar. Teori dan Kasus, Penebar Swadaya.

Daniel, Moehar. 2002. Pengantar Ekonomi Pertanian. Jakarta: PT. Buni Aksara. Edison, ., \& nurfathiyah, pera. (2012). Analisis Permintaan dan Penawaran Beras di Propinsi Jambi. Jurnal Ilmiah Sosio-Ekonomika Bisnis, 15(2). Retrieved from https://online-journal.unja.ac.id/index.php/jseb/article/view/2761

Lim Sanny, 2010. Binus business review. Vol.1 No.1 Mei 2010: 245-251 .2017. Merangin dalam Angka. BPS.

Tim Penyusun. 2017. Programa Penyuluhan Pertanian Desa Dusun Baru. Dinas Tanaman Pangan dan Hortikultura Kabupaten Merangin. 
Jurnal Media Agribisnis Vol. 3 No. 2 Tahun 2018 Hal. 90 - 97

Media Komunikasi Hasil Penelitian Bidang Ilmu Agribisnis

ISSN print 2548-7027

ISSN online 2541-6898

Rika I.K.A Mantiri, Debby Ch. Rotinsulu, Sri Murni. 2016. Analisis Faktor-faktor yang Mempengaruhi Produksi Padi Sawah di Kecamatan Dumoga. https://ejournal.unsrat.ac.id/index.php/jpekd/article/view/10766.

Soekartawi.2002. Analisis Usahatani. Jakarta: Universitas Indonesia.

Salfitri. 2010. Tesis: Dampak program Gerunwah (Gerakan Turun ke Sawah) terhadap peningkatan produksi dan pendapatan petani di Kabupaten Sarolangun. Yogyakarta : Universitas Gadjah Mada.

http://metrojambi.com/read/2017/02/02/18076/untuk-petani-2017-merangindapat-bantuan-500-h-cetak-sawah-baru. 